\title{
Can Flipping the Classroom Change the Traditional Teaching Method of "Economic Research Methods"?
}

\section{Zongyi Chen*}

Qilu University of Technology, Shandong Jinan 250353, China.

Email: millxueshu@163.com

\begin{abstract}
The course "Economics Research Methods" is often unsatisfactory because of its abstract nature and high requirements for students' knowledge reserves. Flipping the classroom has changed the timing of knowledge transfer and knowledge internalization, which is helpful for students to make up for their knowledge reserves, and helps to improve the process of knowledge internalization through active classroom discussions with teachers, and it is more conducive to students to establish economic thinking and knowledge Picture. Of course, "Economics Research Methods" also requires teachers and students to make active and effective adjustments to their roles when carrying out fipped classrooms.
\end{abstract}

Keywords: Economics Research Methods; Flipping Classroom; Role

\section{Difficulties in teaching "Economics Research Methods"}

For the master students of applied economics in China, "Economics Research Methods" is an important professional basic course. However, the important course of "Economics Research Methods" has many difficulties in the teaching process, specifically as follows:

1.1 The course is relatively abstract, and students have poor understanding and absorption in the classroom

"Economics Research Methods" contains a lot of philosophical speculation knowledge, and the focus of this course is to convey a way of thinking and philosophical norms, which is the difficulty of this course. It is often unrealistic for students to accept and learn a way of thinking in a shorter lecture time, not to mention that the course itself is very abstract logical preaching. Therefore, the teaching effect of "Economic Research Methods" is often not ideal.

\subsection{Students' knowledge reserves are often lacking}

This course involves a lot of knowledge in multidisciplinary fields such as philosophy of science, history of scientific development, and modern and modern philosophy. However, ordinary master students in economics lack exactly similar knowledge reserves. For example, "Economic Research Methods" involves philosophical knowledge points such as positivism, pragmatism, and normatism. The breadth and difficulty of this knowledge cannot be provided by the general education in the domestic university education stage. Therefore, in the course of learning courses, master students tend to stagger while not interested.

\section{Flipping the classroom may bring changes to the teaching of "Economics Research Methods"}

The so-called flip classroom means that in an information environment, course teachers provide learning resources with teaching videos as the main form. Students complete the viewing and learning of teaching resources such as Copyright (C) 2020 Zongyi Chen

doi: $10.18282 /$ le.v9i5.1193

This is an open-access article distributed under the terms of the Creative Commons Attribution Non-Commercial License

(http://creativecommons.org/licenses/by-nc/4.0/), which permits unrestricted non-commercial use, distribution, and reproduction in any medium, provided the original work is properly cited. 
teaching videos before class. Teachers and students complete their homework questions and answers together in the classroom. A new teaching model for activities such as collaborative inquiry and interactive communication.

Generally speaking, the teaching process usually includes two stages of knowledge transfer and knowledge internalization. In the traditional teaching method, knowledge transfer is accomplished by the teacher's teaching in the classroom, and knowledge internalization requires students to do it through homework, operation or practice after class. Flipping the classroom overturns the traditional teaching process. Knowledge transfer is accomplished after the class with the help of information technology, and knowledge internalization is completed in the classroom with the guidance and help of the teacher and the assistance of classmates.

The introduction of flipped classrooms will not only completely change the teaching method of "Economic Research Methods", but also greatly improve the teaching effect of the course. Because in a short classroom time, master students will be exposed to a large number of new knowledge concepts and knowledge systems, and through these concepts and systems to build their own economic research method models. The process of imparting knowledge is both tedious and requires a high degree of concentration. The process of internalizing knowledge is even more difficult. Once the thinking of logical deduction is interrupted, the students' sense of acquisition is often very low. The introduction of the flipped classroom has completely transformed the process of knowledge transfer and knowledge internalization: after class, students can find relevant auxiliary materials themselves in addition to reading or watching video materials according to their own knowledge reserves, so as to achieve a fully comprehensive Absorb relevant knowledge; in the classroom, due to the large gap in knowledge reserves and differences in thinking between teachers and students, teachers can represent the model of economic research methods that students should establish to a certain extent. Students can ask questions or assumptions in the classroom and let the teacher answer them, so as to quickly and effectively break through the barriers of logical thinking. And this question is often universal, and other students will also benefit from answering the question.

Therefore, in theory, flipping the classroom may completely change the teaching method of "Economic Research Methods" and greatly improve the teaching effect of the course.

\section{3. "Economics Research Method" flips the transformation of the roles of teachers and students in the classroom}

\subsection{Change of teacher role}

The introduction of the flipped classroom has made teachers change from the knowledge transmitters in the traditional classrooms to the guides and mentors of student learning. The introduction of the flipped classroom approach is not about the relaxation and liberation of teachers. On the contrary, flipped classrooms require teachers to reposition their role-playing and embed themselves into the whole process of building a student's knowledge system. Therefore, teachers must pay attention to empathy, take students' knowledge reserves and academic literacy as the coordinates, and re-examine how "Economic Research Methods" should carry out teaching interaction. When preparing course materials, try to provide "one-stop" information, that is, to provide essential and comprehensive information. Essential information is to help students understand the relevant knowledge system in the shortest time, and comprehensive information provides basic concept analysis, knowledge structure association and knowledge system construction maps required by students at different levels. In the classroom, teachers should make a good plan for the course, establish a database of various questions involved in the course, and actively guide students to ask questions while being able to better answer and guide students to establish knowledge maps and thinking habits. At the same time, teachers should also give an objective and timely evaluation of students' performance, to maximize the enthusiasm of students to participate in the curriculum.

\subsection{The change of student role}

In the flip learning teaching method, the student becomes the leader of the entire learning process. The student himself can choose the learning time and learning place, and at the same time can control the learning content and learning volume. The increase in degrees of freedom makes it possible for some students to find it difficult to switch 
roles in the short term. However, postgraduate study is to change a student from a passive learner to an active learner, or even to an efficient learner. Therefore, students must be responsible for their own learning effects, actively invest in the study of "Economic Research Methods", and strive to consult and master the relevant knowledge framework after class, and accurately locate all the logical barriers in the process of building their own knowledge map point. In the classroom, students should take the initiative to fully communicate with teachers and other students, and try to make all the barriers open.

\section{Conclusion}

The course "Economics Research Methods" is too abstract, and at the same time has high requirements for students' knowledge reserves. Practice has shown that although teachers' teaching willingness and educational efforts are very high, the teaching effect is often poor. As a new teaching method, flipping the classroom has completely changed the timing of knowledge transfer and internalization of knowledge, so that students have enough time to make up for the lack of knowledge reserves, and carry out active discussions with teachers through the classroom, which are beneficial to students Establish economic thinking and knowledge. At the same time, teachers and students must make active and effective adjustments to their roles in order to ensure the effective development of the flipped classroom.

\section{References}

1. Ma Minghai, Qian Liping, She Xinsong, Xu Shengyou, Wan Shunli. Reform and empirical study of science and technology paper writing curriculum based on flipped classroom[J]. Journal of Higher Education, 2020(19): $129-132$.

2. Chen Xiaofei. Research on the flipped classroom teaching model[D]. Central China Normal University, 2014.

3. Liu Jianzhi, Wang Dan. A review of the research and practice of flipping classrooms at home and abroad [J]. Contemporary Education Theory and Practice, 2014, 6(02): 68-71.

4. Li Hailong, Deng Minjie, Liang Cunliang. Design and application of task-based flipped classroom teaching model [J]. Modern Education Technology, 2013, 23(09): 46-51. 